\title{
AMÉRICA LATINA: UMA INTEGRAÇÃO REGIONAL AGÔNICA? A INSTITUCIONALIDADE DA INTEGRAÇÃO REGIONAL E ALGUNS DE SEUS PRINCIPAIS DESAFIOS
}

\author{
Claudete de Castro Silva Vitte \\ Unicamp - Universidade Estadual de Campinas
}

\section{Resumo}

Esta pesquisa enfocou o Acordo Estratégico Transpacífico (TPP/TPP-11), a Aliança Bolivariana para os Povos de Nossa América-Tratado de Comércio dos Povos (Alba) e a Comunidade de Estados Latino-Americanos e Caribenhos (Celac), considerando a institucionalidade de cada organização e suas caracterizações. $\mathrm{Na}$ metodologia de pesquisa foi feito um balanço preliminar da literatura sobre organizações regionais e sobre os casos específicos, em tentativa de correlacioná-las entre si, observando semelhanças e diferenças. Como resultados, verificamos que a arquitetura regional latino-americana é complexa e o regionalismo latinoamericano não vive seu melhor momento. Com crise econômica, os processos de integração regional na América Latina refluem. O cenário político mais instável na região também dificulta a integração regional.

Palavras-chave: Fronteira, Insegurança, Território.

\begin{abstract}
Resumen
Esta investigación se centró en el Acuerdo Estratégico Transpacífico (TPP / TPP-11), la Alianza Bolivariana para los Pueblos de Nuestra América-Tratado de Comercio de los Pueblos (ALBA) y la Comunidad de Estados Latinoamericanos y Caribeños (Celac), considerando la institucionalidad de cada organización y sus caracterizaciones. En la metodología de investigación se hizo un balance preliminar de la literatura sobre organizaciones regionales y también sobre los casos específicos, en intento de correlacionarlas entre sí, observando semejanzas y diferencias. Como resultados, verificamos que la arquitectura regional latinoamericana es compleja y el regionalismo latinoamericano no vive su mejor momento. Con crisis económica, los procesos de integración regional en América Latina refluyen. El escenario político más inestable en la región también dificulta la integración regional.
\end{abstract}

Palabras clave: Frontera, Inseguridad, Territorio.

\section{Introdução}

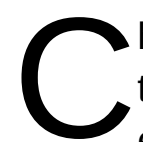

hama a atenção o fato de haver um número significativo de organizações regionais de integração na América Latina, especialmente na América do Sul. Persistem dúvidas se todas elas são relevantes o suficiente para sobreviverem no longo prazo.

Esta pesquisa objetivou contribuir na discussão sobre alguns dos processos de integração que vêm ocorrendo na América Latina, especialmente na América do Sul, focando o Acordo Estratégico Transpacífico, a Alba e a Celac, considerando a institucionalidade e as organizações como 
possibilidade de espaço sociopolítico em construção. Estas organizações regionais estudadas nesta empreitada foram caracterizadas brevemente e foi feita uma breve revisão de estudos recentes sobre elas.

Com relação à metodologia de pesquisa, foi feito essencialmente um balanço preliminar da literatura sobre organizações regionais latino-americanas de forma geral e sobre os casos específicos, em tentativa de correlacioná-las entre si, observando semelhanças e diferenças. Foram feitos levantamentos em livros, periódicos especializados teses e dissertações; na imprensa e consultas a sítios eletrônicos de diversas fontes, das organizações regionais, de instituições financeiras regionais e de algumas chancelarias, como a brasileira.

\section{América Latina: regionalismo pós-liberal e seus labirintos}

Neste artigo, parte-se da ideia que a arquitetura regional latino-americana é complexa e o regionalismo ${ }^{1}$ latino-americano não vive seu melhor momento.

Para José Antonio Sanahuja (2014, p. 86), na América Latina, especialmente na América do Sul, recentemente se observa "una reinterpretación del regionalismo que podría caracterizarse como 'postliberal' por tratar de trascender el modelo del regionalismo abierto" vigente desde a década de 1990.

O chamado regionalismo pós-liberal se fundamenta na intenção de tornar realidade os objetivos de autonomia, projeção internacional, desenvolvimento econômico e social e de uma governança interna no subcontinente que, como lembra o autor, "anima el regionalismo latinoamericano desde sus orígenes", exprimindo também a diversidade, a complexidade e a heterogeneidade que caracterizam o regionalismo na América Latina na atualidade (SANAHUJA, 2014, p. 86).

Assim, frente à diversidade de organizações regionais vigentes na América Latina (e do Sul) há autores, como Rafael Duarte Villa, que consideram que há blocos que precisarão ser, "ainda que não eliminados, ao menos repensados, para não parecerem elefantes brancos adormecidos" (entrevista de Rafael D. Villa a Paula Adamo IDOETA, 2011, s/p), enquanto outros consideram positiva a diversidade, de forma que "es posible que emerjan distintas configuraciones de formaciones regionales, aún con acuerdos que se superponen [...] ya que [...] privilegian formas particulares de movilización de ideas y actores en la práctica de política regional" (RIGGIROZZI \&TUSSIE, 2018, p. 19).

\footnotetext{
${ }^{1}$ A despeito das controvérsias que cercam estas definições, como aponta Yann Richard (2014), tomaremos o entendimento de Peter Birle (2018) para explicar regionalismo e regionalização em perspectiva das Relações Internacionais. Ele explica, apoiado em Börzel e Risse: "el regionalismo es entendido como un proceso liderado principalmente por los Estados y sus gobiernos para construir y sostener instituciones y organizaciones regionales formales. Por el contrario, el término regionalización se refiere a procesos que llevan al aumento de las interacciones económicas, políticas, sociales o culturales entre estados y sociedades geográficamente o culturalmente contiguos). La regionalización se refiere sobre todo a actividades transnacionales de abajo hacia arriba de actores no estatales como grupos de interés, movimientos sociales, empresas y organizaciones no gubernamentales" [sem grifo no original] (BIRLE, 2018. p. 248). Outra definição de regionalismo: O regionalismo pode ser entendido como "una forma de coordinación transfronteriza que articula actores e instituciones en diferentes áreas de política de manera de dar respuesta a problemas comunes. Dicha coordinación puede darse en una variedad de campos y asumir diferentes grados de institucionalización, formalización y organización" (RIGGIROZZI \& TUSSIE, 2018, p. 08).
} 
Na sequência, foram feitas algumas considerações sobre as organizações regionais ou iniciativas de integração acima assinaladas, enfatizando-se o contexto após 2013, quando a crise econômica e política no subcontinente se fazem mais evidentes.

\section{O Acordo Estratégico Transpacífico (TPP)}

Uma iniciativa de organização de um megabloco comercial que envolve a participação de países latino-americanos e que vem causando muitas discussões é o Acordo Estratégico Transpacífico, assinado em junho de 2012 com a participação dos países latino-americanos Chile, Peru e Méxi$\mathrm{CO}^{2}$. De fato, este Acordo entrou em vigor em 2015, mas sofreu revés em 2017, quando o recém empossado presidente norte-americano, Donald Trump, retirou os EUA do Acordo, até então o grande protagonista desta integração extra-regional ${ }^{3}$.

Intercâmbios de bens, livre mobilidade de pessoas, integração financeira, fortalecimentos de pequenas e médias empresas e cooperação em educação foram pautas de discussão, com a formação de grupos técnicos e alguns objetivos específicos. Para Mariano Turzi (2015), o

Acuerdo Estratégico Transpacífico de Asociación Económica (TPP) tendrá implicancias determinantes no solo para el futuro de la economía internacional, sino del orden global. En ese sentido, su consolidación o estancamiento determinará en gran medida el devenir de la integración regional latinoamericana. Esta nueva realidad transformadora de los asuntos globales tendrá consecuencias decisivas para las estrategias de acción e inserción externa de gobiernos y compañías en América Latina. Si en el siglo $X X$ el Canal de Panamá marcó la separación del continente americano en norte y sur, en el siglo XXI el TPP está introduciendo un nuevo vector al proceso de integración latinoamericano, dividiendo a la región en este y oeste, o Pacífico y Atlántico. El riesgo para América Latina es que esa división se traduzca en diferencias de regionalización y divergencias de regionalismo (TURZI, 2015, p. 01).

Acompanhando ainda a interpretação de Mariano Turzi sobre o Acordo Transpacífico (TPP), este autor alerta que ela deve ser entendida como o processo crescente de transnacionalização e que isso impacta diretamente a regionalização latino-americana, por ocorrer nesta etapa do capitalismo globalizado que é organizado ao redor de cadeias de valor e essa realidade deverá impactar os padrões de inserções nacionais, com possíveis mudanças de custos e benefícios, com "realineamiento de intereses y estrategias a las nuevas oportunidades y amenazas", "generando nuevas geografías económicas" (TURZI, 2015, p. 02).

Mariano Turzi conclui e ao mesmo tempo alerta que o Acordo Transpacífico não é um acordo para criar comércio, mas para administrar comércio e finanças. Ele "constituye un movimiento de retaguardia más que de avance; la gestión de un poder declinante más que el desplie-

\footnotetext{
2 Em 2015, segundo Mariano Turzi (2015, s/p) faziam parte do "Acuerdo Estratégico Transpacífico de Asociación Económica (TPP) 12 países: Australia, Brunei, Canadá, Chile, EE.UU., Japón, Malasia, México, Nueva Zelanda, Perú, Singapur y Vietnam. Y se han alineado ya otros posibles candidatos como Corea del Sur, Taiwán, Filipinas y Colombia". ${ }_{3}$ Conforme Carolina Zaccato (2018), "el TPP constituyó una de las grandes apuestas de la administración de Barack Obama, dentro de lo que se conoció como su política de pivot asiático, enfocada en no perder gravitación en la cuenca pacífica".
} 
gue de un poder ascendente", de forma que sem considerar as diferenças iniciais, a competição "juega a favor de las asimetrías existentes" (TURZI, 2015, p. 03).

Cabe observar que o Acordo Transpacífico (TPP) logo após a saída dos EUA passou a ser denominado por Tratado Integral Progressista da Associação Transpacífico (CPTPP), mais conhecido por TPP-11. Segundo Carolina Zaccato (2018),

en una cumbre celebrada en la ciudad chilena de Viña del Mar, estos once países comenzaron a trazar un plan para mantener vivo el proyecto de un mega bloque comercial que atravesara la Cuenca del Pacífico. En las reuniones subsiguientes, celebradas en Canadá, Vietnam y Japón, se delineó lo que hoy es el TPP-11. De este modo, de lo que originariamente había sido un proyecto surgido de un liderazgo hegemónico de los Estados Unidos, se pasa a una situación de liderazgo compartido con fuerte impulso desde las principales potencias del acuerdo (Australia, Canadá y Japón) y los referentes latinoamericanos del grupo (Chile y México) para no dejar caer aquel mega proyecto comercial y económico. Finalmente, el 8 de marzo de 2018 se firmó en Chile, el Tratado Integral y Progresista de Asociación Transpacífico (TPP-11) (ZACCATO, 2018, p. 195).

O TPP-11 representa na atualidade $13,5 \%$ do produto mundial e $15,3 \%$ do comércio internacional, com mercado potencial de 495 milhões de pessoas, enquanto que o TPP que incluía os EUA compreendia $40 \%$ do produto mundial e mais de $25 \%$ do comércio internacional (ZACATTO, 2018, p. 195). Na opinião de Carolina Zaccato (2018), que demonstra simpatia por este Acordo, o TPP-11 continua sendo um acordo de integração muito relevante mesmo sem a presença norteamericana, não apenas pelas suas dimensões, diversidade geográfica e econômica de seus membros. É um exemplo do que se denomina "Regionalismo do Século XXI", que pode ser entendido como

aquellas iniciativas comerciales que buscan zanjar la brecha que existe dentro de una realidad en la que se comercia con desafíos y problemáticas inherentes al siglo XXI, pero con reglas del siglo XX. En este sentido, acuerdos como el TPP-11 ya no solo involucran el comercio de materias primas y manufacturas, sino que también incorporan flujos multidireccionales de ideas, servicios, personas, e inversiones en capital físico y humano; además de proponerse impulsar la construcción de cadenas globales de producción, distribución y diseño. Con ello, el regionalismo del siglo XXI pone el acento ya no solo en la reducción de tarifas sino principalmente en construcción y armonización de estándares y regulaciones, la creación de condiciones favorables para el desarrollo económico y la atracción de inversiones, y facilitar la interconexión entre los distintos eslabones de cadenas de producción que son, hoy en día, cada vez más internacionalizadas (ZACCATO, 2018, p. 196).

E, assim, esta Aliança continua firme e forte, com novos protagonistas, a mesma ambição e pouca discussão sobre seus impactos socioambientais. ${ }^{4}$

\footnotetext{
${ }^{4}$ Sobre controvérsias sobre os impactos sociais deste Acordo, Leandro Morgenfeld (2016) aponta alguns dos impactos econômicos e sociais para países participantes, em especial países menos desenvolvidos. Ele alerta: "para los países menos desarrollados, implicará una mayor desindustrialización, apertura irrestricta de sus economías, pérdida de sobe-
} 


\section{A Alba-TCP (Aliança Bolivariana para os Povos de Nossa América - Tratado de Comércio dos Povos)}

Como bem lembra Daniele Benzi (2016, p. 77) a Alba-TCP, criada em 2004, em Havana, "es la propuesta de integración que más optimismo suscitó en la izquierda radical latinoamericana y mundial". A Aliança Bolivariana para os Povos de Nossa América -Tratado de Comércio dos Povos (Alba-TCP) é um exemplo da chamada integração pós-liberal. Segundo Miriam Saraiva (2011), esta Aliança surgiu como alternativa à área de livre comércio proposta pelos EUA para a América Latina, visando convergir em um discurso denominado de bolivariano, que teve sua gênese na Venezuela no início do século XXI (SARAIVA, 2011, p. 11).

$\mathrm{Na}$ interpretação da autora acima, os países que compõe esta Aliança defendem criar um tipo de confederação latino-americana de conteúdo majoritariamente político e com sua criação seus membros passaram a demonstrar de maneira incisiva ser a Aliança um instrumento antineoliberal e anti-norte-americano, aspirando aprofundar um "processo revolucionário" interno e externo aos países membros. Há, então, um objetivo eminentemente político de assegurar, por meio da Aliança, maior poder e autonomia dos países membros nos cenários globais com a dimensão econômica da integração subordinada à dimensão política ideológica e militar ${ }^{5}$, com o propósito de promover a equidade, igualdade, lealdade e unidade de propósitos, atraindo a Bolívia e o Equador como solidários a esses princípios e objetivos (SARAIVA, 2011, p. 08-09).

Por ser a Venezuela, país que concebeu esta estratégia de integração, também caribenho, o arco de ação abarca também para aquela parte do subcontinente. Sua institucionalidade começou em 2014 e conta com um Conselho de Presidentes, um Conselho de Chanceleres, uma coordenação permanente que administra os projetos e comissões setoriais (SARAIVA, 2011, p. 11). Observe-se que a Aliança criou, em 2008, um banco de fomento, o banco Alba, que teve um capital inicial de um bilhão de dólares (U\$1.000.000.000) (FREITAS, 2011, p. 09). ${ }^{6}$

Completando a caracterização da Alba, Miriam Saraiva fala que a Aliança se operacionaliza por meio de tratados de comércio entre os membros sempre incluindo empresas estatais mis-

\footnotetext{
ranía económica, peores condiciones para que los estados establezcan regulaciones, por ejemplo en materia laboral o medioambiental, o para avanzar en la producción de medicamentos genéricos. Como los demás acuerdos de libre comercio, otorgan libertad al movimiento de capitales y mercancías, pero no de personas, alentando la baja de salarios y la flexibilización laboral. Si los trabajadores establecen resistencias, se amenaza con la relocalización de las empresas, hacia entornos donde la flexibilización laboral sea mayor y los salarios más bajos, como ocurrió en las últimas dos décadas con el NAFTA" (MORGENFELD, 2016, p. 100).

5 Julia Teresa Eder (2016) compartilha em parte desta visão da supremacia do político sobre o econômico na concepção da Aliança. Segundo esta autora, "ALBA-TCP constitutes a special form of post-liberal integration, which adopts principles of socialist integration theory, but tries to implement them under capitalist surroundings. There has been a strong economic element in the initial design and in the evolution of the integration. The huge difference to other forms of integration is the role assigned to economy in relation to other dimensions of society. Increasing trade and economic growth are not seen as the main goals of the integration process. They are just means to meet the needs of the people" (EDER, 2016, p. 04).

${ }^{6}$ William Daldegan de Freitas explica que "em 2005, na cidade de Puerto La Cruz, Venezuela, são criados a PETROCARIBE e o Fundo Alba - Caribe para o Desenvolvimento Econômico e Social. Subscreveram este acordo os representantes de Antígua e Barbuda, Bahamas, Belize, Cuba, Dominica, Granada, Guiana, Jamaica, República Dominicana, São Vicente e Granadinas, Santa Lúcia, São Cristóvão e Neves, Suriname e Venezuela. Cabe ressaltar que nem todos os países que assinaram o acordo de criação deste órgão estão sujeitos as diretrizes do bloco bolivariano, ou que intentem sua adesão, não excluindo essa possibilidade. Em 2006, Bolívia integra o bloco e dão-se início aos debates sobre a implementação do Tratado de Comércio entre os Povos (TCP)" [sem grifo no original] (FREITAS, 2011, p. 05-06).
} 
tas, denominadas de grannnacionais, e por projetos coletivos orientados principalmente para os países de menores recursos que procuram aproveitar vantagens comparativas preexistentes e que incluem trocas de bens e serviços, facilitação de pagamentos e transferência tecnológica (SARAIVA, 2011, p 11-12). William Daldegan de Freitas (2011) comenta o papel das chamadas empresas grannacionais, como é o caso da Petrocaribe. São empresas com ações orientadas para o comércio intra-bloco e cuja atuação é uma forma dos estados retomarem o papel de indutores do desenvolvimento. Ele explica que,

as empresas grannacionais fazem alusão a integração e conformação de uma grande nação latino-americana e caribenha, fundamento da visão bolivariana e expressa na VI Cúpula da ALBA de 2009. Esta iniciativa seria a chave do sucesso da ALBA, pois, permitiria um novo regionalismo baseado no provimento a partir de empresas públicas onde os diferentes interesses nacionais convergiriam e a associação para a criação das empresas e projetos grannacionais colaborariam para o avanço do desenvolvimento dos países envolvidos, já que proveriam o mercado intra-bloco (FREITAS, 2011, p. 09-10). ${ }^{7}$

Para Miriam Saraiva (2011), na Alba há uma diplomacia social que "baseia-se em recursos provenientes do petróleo venezuelano e na ação clara da Venezuela como paymaster, junto com um papel central também de Cuba com contribuições nas áreas de saúde e educação" (SARAIVA, 2011, p. 12) e por meio de um discurso de solidariedade e apoio aos países menores cria-se uma ressonância para o chamado "socialismo venezuelano". Mas, é uma organização de caráter intergovernamental que não inclui uma dimensão supranacional e que não prevê partilha de soberania (SARAIVA, 2011, p. 12).

Cabe também apontar um aspecto relevante da constituição desta Aliança, apontado por William Daldegan de Freitas (2011), o qual assevera que

a região que compreende a ALBA é uma importante porção do território mundial onde encontram-se importantes recursos energéticos vitais para o desenvolvimento mundial e o bloco entende isso como uma oportunidade para iniciativas que integrem ainda mais a região. Segundo palavras de Bendaña (2008) seria 'a decisão política de usar as massivas reservas de óleo e seus ganhos na assistência de outros estados do mundo com o claro objetivo de reduzir sua dependência da ordem internacional comercial e financeira dominante' (BENDAÑA apud FREITAS, 2011, p. 10-11).

Em visão otimista sobre a Alba, Julia Theresa Eder (2016) defende que

far away from being a perfect archetype of a regional integration, ALBA-TCP provides interesting new considerations of how integrational efforts can be organised: "ALBA's emphasis on public rather than private ownership, domestic rather than export orientation, social rather than profit motivation, and solidaristic rather than

\footnotetext{
${ }^{7}$ O autor defende que a criação de empresas grannacionais visou torná-las provedoras do mercado interno dos países membros por meio da união das capacidades produtivas, visando oferecer suprimentos por valores não acrescidos da mais-valia, demonstrando a busca por um desenvolvimento autônomo pelo bloco (Freitas, 2011, p. 08). Ele cita o caso do "projeto da Grannacional de Alimentos, em que a produção de soja boliviana seria incrementada e atenderia os mercados regionais, facilitando a distribuição e comercialização, sem o intercâmbio de empresas transnacionais que inflariam o custo do produto" (FREITAS, 2011, p. 09-10).
} 
competitive relationships provides an important (ideological and material) counterweight to capitalist imperatives. It also represents an example of how states can create regional institutions that are capable of strengthening nationally centered development efforts" (EDER, 2016, p. 03).

Daniel Benzi, por outro lado, faz uma interpretação crítica desta Aliança. ${ }^{8}$ Ele avalia os resultados da integração proposta por esta Aliança apontando, dentre vários fatores, a lógica rentista da política externa da Venezuela, as limitadas possibilidades de complementação entre economias agrário-exportadoras e uma falta de clareza no que se refere a sua perspectiva políticoideológica e econômica.

O autor localiza na Aliança a visão de integração formulada pelo ex-presidente venezuelano Hugo Chávez de um projeto político com transbordamento para o contexto regional. Desta forma, para o autor:

Bajo la égida de la "Patria Grande", entre los años 2005 y 2010 el gobierno bolivariano desplegó una intensa actividad internacional paralela a la reformulación de su proyecto de nación hacia la edificación del "socialismo del siglo XXI". El resurgimiento de cierto mesianismo inspirado en la figura del Libertador Simón Bolívar y el peculiar matrimonio con Cuba tuvieron una influencia decisiva en ambas orientaciones. El incremento sin precedentes de la renta petrolera le proporcionó solvencia, capacidad de acción y hasta credibilidad en un primer momento (BENZI, 2016, p. 77).

Com a ampliação de países-membros e de atividades a organização mudou-se de Alternativa para Aliança e se assumiu como um bloco bolivariano em um "nuevo concierto regional, alabando sus virtudes revolucionarias o bien advirtiendo acerca de los peligros que la opción "neopopulista' comportaría en el ya fragmentado panorama de la integración” (BENZI, 2016, p. 78-79).

Baseando na análise de Steve Ellner, Daniel Benzi, alerta para um fator que condiciona, quando não determina, todos os projetos regionais impulsionados pela República Bolivariana da Venezuela que é o fato da total dependência das rendas advindas do petróleo, em claro exemplo da chamada "doença holandesa". Ele fala que

aun con la mayor reserva de crudo pesado del planeta, que alienta las fantasías de una "potencia energética mundial", se trata de la dependencia absoluta de un único recurso y de la ausencia de ventajas en otros sectores de la economia. Aunque no menciona el rentismo petrolero como tal, esta mirada revela la otra cara de un elemento que, cuestionado a lo sumo por su impacto ambiental o uso "políticamente no correcto", por lo general ha sido asumido positivamente en la izquierda en razón de las capacidades poseídas por Venezuela en el sector del petróleo y derivados (BENZI, 2016, p. 83).

\footnotetext{
${ }^{8} \mathrm{O}$ autor justifica seu esforço de crítica, afirmando que "empezando con una síntesis del debate sobre el Alba-tcp en la cual explicito mi posición, en las páginas siguientes propongo un esbozo de lo que debería considerarse la 'anatomía de la integración que no fue'. Ello, con el objetivo de estimular la discusión sobre las falencias, las omisiones y los errores cometidos, ahora que la viabilidad de la integración 'alternativa', quizás por un buen tiempo, se verá drásticamente limitada" (BENZI, 2016, p. 79), posição a qual compartilhamos.
} 
Daniel Benzi menciona outros limites e críticas à Aliança, entre os quais relativos ao seu eixo social, fundamentado na conceituação de diplomacia social, comentando alguns programas educacionais e médicos, reconhecendo avanços, mas apontando dificuldades. Ele considera que

se trata de "aportes solidários" a disposición de los Ejecutivos, canalizados sin controles o auditorías parlamentarias, administrativas o de la sociedad civil, que se prestan a denuncias por la escasa transparencia en su manejo. Aún falta una investigación comparativa sobre su recepción y gestión en los integrantes del Alba. No obstante, numerosos indicios sugieren que en Bolivia, Nicaragua y Honduras (antes del golpe) han servido como un asunto cuasi privado de los mandatarios $y$ sus entornos para financiar programas de transferencias directas y obras de infraestructura con un claro sesgo partidista. ... El impacto político y social fue inicialmente muy apreciable, como complemento a las políticas de transferencias condicionadas de los gobiernos nacionales. Sin embargo, al igual que en los programas aplicados en Venezuela, la falta de continuidad y seguimiento, así como la transparencia y el rigor exiguos en la presentación de costos y resultados, me-noscabó el potencial y la legitimidad de la cooperación. Su institucionalización ha sido débil, en todo caso [sem grifo no original] (BENZI, 2016, p. 85-86).

Continuando seu intento de apresentar uma interpretação crítica sobre a Alba, Daniel Benzi também considera que

gracias al boom petrolero, además de las estrategias mediática y diplomática, varias formas de "aportes solidários" fluyeron copiosamente desde Caracas hacia las naciones "hermanas" para divulgar una imagen positiva del proceso bolivariano $y$, de paso, comprar a poyos. Eso ayuda a explicar también un desarrollo institucional débil y la adhesión de países que presentan porcentajes elevados de pobreza y dependencia de la asistencia internacional. Pero al considerar irrelevantes o secundarios a los actores no estatales y las metas de integración ... dificulta una comprensión más abarcadora (BENZI, 2016, p. 81).

Outra questão relevante é observar que há um caráter centralizador e burocrático dos governos da Alba que torna esvaziado de sentido ditames constitucionais e os ensaios de democracia participativa, ocorrendo de forma mais efetiva um reforço do poder dos partido e suas máquinas eleitorais, "bajo una lógica de control y cooptación de las organizaciones sociales" concluindo que un "poder popular" articulador de instancias gubernamentales y movimientos en la perspectiva de una "diplomacia de los pueblos", se ha revelado por diferentes razones muy problemática y ha quedado básicamente incumplida" (BENZI, 2016, p. 86).

Assim, o cenário atual da América Latina em seu contexto hemisférico traz muitos desafios para a proposta da Alba. 


\section{A Celac (Comunidade de Estados Latino-Americanos e Caribenhos)}

Em breve retrospectiva sobre a criação da Celac, que sucedeu a Cúpula de Chefes de Estado e de Governo da América Latina e Caribe sobre Integração e Desenvolvimento (CALC), pode-se afirmar de forma resumida que

em dezembro de 2008, o Brasil tomou a iniciativa de convocar a primeira Cúpula de Chefes de Estado e de Governo da América Latina e Caribe sobre Integração e Desenvolvimento (CALC), que se realizou na Costa do Sauipe, Bahia. O objetivo foi estabelecer um processo de cooperação que abrangesse toda a região latinoamericana e caribenha. A principal virtude da CALC foi reunir, pela primeira vez, todos os 33 países latino-americanos e caribenhos, que não se encontravam juntos sem a presença de países de fora da região em outros mecanismos. ... A CALC foi, portanto, a primeira oportunidade que os países da região tiveram para se reunir e refletir sobre o desenvolvimento e a integração a partir de uma agenda própria, moldada de acordo com os interesses das sociedades latino-americanas e caribenhas. Em fevereiro de 2010, no México ... foi aprovada a ideia de reunir progressivamente o Grupo do Rio e a CALC no marco de um único foro, intitulado Comunidade de Estados Latino-Americanos e Caribenhos (CELAC) (BRASIL. ITAMARATY, s/d. Disponível em: http://www.itamaraty.gov.br/pt-BR/politicaexterna/integracao-regional/689-comunidade-de-estados-latino-americanos-ecaribenhos).

Segundo José Antonio Sanahuja (2014), a institucionalização da Celac é relevante porque ela se firma em seu pleno alcance regional: todo continente americano, com exceção dos EUA e do Canadá, faz parte da Comunidade, que intenciona ser um marco de concertação e de cooperação dos distintos países membros e de seus agrupamentos sub-regionais.

O desafio da Comunidade é de formular acordos e estratégias comuns que considerem a pluralidade de visões e ações políticas, econômicas e sociais que já coexistem na América Latina. Daí o seu lema: "Unidade na Diversidade", expressando a própria visão da Organização sobre si mesma (SANAHUJA, 2014, p. 93).

Entre as principais anseios e preocupações da Comunidade observem-se: a reafirmação democrática, a busca de integração baseada em cooperação e solidariedade, a geração de oportunidades para o desenvolvimento, a ampliação da interlocução no sistema internacional, a defesa do direito internacional e a consolidação da América Latina como região de paz (ARAVENA, 2012, p. 25).

A ideia de comunidade regional, que dá origem ao nome desta Organização, pressupõe amplificar as oportunidades de construção da identidade latino-americana e há a pretensão dela ser representativa e ter legitimidade de expressar ou de vocalizar de forma unívoca visões dos governos, dos parlamentos, das empresas, das organizações internacionais regionais e dos cidadãos (ARAVENA, 2012, p. 25). 
José Antonio Sanahuja (2014) assinala o papel identitário da Celac em seu esforço em construir um discurso uníssono para os países da região e da necessidade de cautela para não exterminar organizações regionais pré-existentes. Para ele, de fato

CELAC no pretende sustituir a los grupos subregionales existentes, y bajo el principio de "complementariedad" pretende, más bien, que estos puedan actuar en un marco común, y que la cooperación funcional o temática que pueda definirse en el marco de CELAC se desarrolle a través de esos grupos o de otras instituciones regionales como CEPAL o el Sistema Económico Latinoamericano (SELA), que parece haber encontrado una nueva razón de ser respondiendo a los requerimientos de apoyo técnico de CELAC y, con ello, salir de la situación de letargo y crisis misional en la que se encontraba en las últimas décadas (SANAHUJA, 2014, p. 93).

Assim, considerando-se a dimensão intrarregional, a Celac pode ser vista como um "mecanismo de provisión de bienes públicos regionales y en particular aquellos relacionados con el desarrollo, la paz, la estabilidad política y la democracia"9 (ARAVENA apud SANAHUJA, 2014, p. 95). E, não menos importante:

CELAC también asume funciones de gestión de crisis y de promoción y defensa de la democracia ante el riesgo de involución política, sin perjuicio de las que también ha asumido la OEA u otros organismos regionales como Mercosur o UNASUR, dando así a la región mayores opciones de actuación (SANAHUJA, 2014, p. 95).

$\mathrm{Na}$ Celac há um mecanismo de concertação e cooperação não institucionalizado, com alcance eminentemente político, conforme fala José Antonio Sanahuja (2014), e que contrasta com a OEA (Organização dos Estados Americanos) e com a Unasul, pois ela

ni tiene un tratado constitutivo ni constituye una organización internacional, lo que de nuevo expresa la preferencia de la región por un intergubernamentalismo que no comporta ninguna limitación de la soberanía nacional de cada Estado, y en suma, por un regionalismo "ligero" con un reducido nivel de institucionalización y la primacía del principio de soberanía nacional (SANAHUJA, 2014, p. 96).

Desta forma, conforme assevera Antonio Sanahuja (2014) a Celac representa

una expresión más de la "Diplomacia de Cumbres", de fuerte impronta presidencial, que ha dominado las relaciones intrarregionales e interregionales en las que participa la región, como es el caso de las Cumbres que de manera creciente marcan las agendas de política exterior de la región y presiden y dan impulso político

\footnotetext{
9 A respeito dos mecanismos de tomada de decisões, principalmente no que se refere a gestão de riscos e de crise, José Antonio Sanahuja (2014, p. 95-96) explica que a Comunidade se organizou com os seguintes órgãos: "la Presidencia Pro témpore, que se ejerce anualmente, y una Troika integrada por la Presidencia en ejercicio, la precedente, y la posterior; el Consejo de Jefes de Estado y de Gobierno, con reuniones ordinarias anuales y la posibilidad de celebrar reuniones de carácter extraordinario convocadas por la Presidencia en consulta con la Troika y los Estados miembros; la reunión de Ministros de Relaciones Exteriores, con reuniones ordinarias bianuales y de carácter extraordinario a solicitud de un Estado miembro; la reunión de coordinadores nacionales, compuesta por funcionarios de alto nivel, que también realiza reuniones bianuales; y reuniones especializadas, de rango ministerial o de grupos de trabajo de altos funcionarios. En esos órganos, la toma de decisiones se regirá por la regla del consenso y dará lugar a resoluciones, posiciones comunes, acuerdos y mandatos de naturaleza política".
} 
a los diferentes agrupamientos regionales - Mercosur, CAN, SICA, Caricom, ALBA-TCP, Alianza del Pacífico y UNASUR - y a sus relaciones extra e interregionales, a través de las Cumbres de las Américas, las Cumbres UE-América Latina y el Caribe, y las Cumbres Iberoamericanas (SANAHUJA, 2014, p. 92).

Alguns percalços dificultaram uma efetiva atuação da Celac, não tendo sido explorado um papel previsto de ser um mecanismo chave de reconfiguração regional, como havia pensado o presidente Lula da Silva, "orientada pela alteridade em relação aos Estados Unidos e à Organização dos Estados Americanos, e com vistas a dar maior institucionalidade a um mecanismo que incluísse a Cuba entre seus membros" (SARAIVA, 2016, p. 298).

O fato é que eventos como o impeachment do presidente Fernando Lugo do Paraguai (em 2012) e a crise política da Venezuela foram discutidas e negociadas no âmbito da Unasul e não da Celac.

Assim, a Celac parece apresentar maiores dificuldades em lidar com as diferenças existentes entre os países latino-americanos e, aspecto notável, "a situação da Celac e da Unasul é de sobreposição, onde a principal lealdade brasileira se orienta para a América do Sul" (SARAIVA, 2016, p. 305).

\section{Considerações finais}

A integração regional sul-americana e latino-americana revela que transformações históricas têm gerado "un complejo mapa de la integración latinoamericana con una arquitectura multinivel", resultante de interesses econômicos e propósitos geopolíticos e ideológicos que resultam em alianças variadas e estratégias de equilíbrio de poder, de forma que algumas dessas organizações são mais liberalizantes, outras mais protecionistas (AYUSO, 2016, p. 46-47).

A América Latina, e a América do Sul em especial, tem organizações de integração regional com uma marca muito peculiar: são instituições presidencialistas, com um "exacerbado intergovernamentalismo" no qual as decisões importantes são tomadas por unanimidade e consenso em alto nível.

Os processos de integração em curso na América do Sul e na América Latina aspiram blindar os países membros da espoliação internacional, de interesses extra-regionais, com o reflorescimento de discursos anti-imperialistas vertebrando alguns dos acordos regionais implementados a partir do final do século XX. No entanto, os posicionamentos e práticas nacionais no subcontinente são diversos e muitos países da região permanecem buscando acordos bilaterais com países extra-regionais, em especial com os EUA, casos da Colômbia e Chile, entre outros, em nítida contradição com o discurso bolivariano.

Ademais, em contexto de crise econômica, os processos de integração regional na América Latina refluem. O cenário político mais instável na região dificulta se encontrar um ponto de equilíbrio para diferentes demandas e interesses nacionais e de serem aceitas, sem contestação de diversos segmentos sociais nacionais, medidas coletivas de âmbito regional que implicam em 
uso de recursos que poderiam ser aplicados em políticas nacionais oriundas de demandas eleitorais e de grupos de interesses vulneráveis à crise.

Aprovado pela Comissão Científica do III CONGEO - Congresso Brasileiro de Geografia Política, Geopolítica e Gestão do Território Universidade Federal Fluminense - Niterói (RJ), 2018 


\section{Referências}

AYUSO, Anna. El Espacio Iberoamericano en el Orden Global. In: SORIA, Adrián Bonilla; SAÉNZ, Stella; MORALES, María Fernanda (Eds.). Iberoamérica: y el nuevo regionalismo. San José (Costa Rica): FLACSO, 2015.

ARAVENA, Francisco Rojas. La Celac y la integración latinoamericana y caribeña: Principales claves y desafíos. Nueva Sociedad, n, 240, julio-agosto de 2012. Disponível em: <http://nuso.org/media/articles/downloads/3877_1.pdf>. Acesso em: 23 mai. 2018.

BENZI, Daniele. El exitoso ocaso del ALBA: Réquiem para el último vals tercermundista. Nueva Sociedad $n^{\circ}$ 261, enero-febrero 2016. Disponível em: <http://nuso.org/articulo/el-exitosoocaso-del-alba/>. Acesso em: 20 mai. 2018.

BIRLE, Peter. Cooperación e integración regional en América Latina: entre la globalización y la regionalización. In: Andrés Serbin (Editor). América Latina y el Caribe frente a un Nuevo Orden Mundial: Poder, globalización y respuestas regionales. Barcelona: Icaria Editorial: Coordinadora Regional de Investigaciones Económicas y Sociales - CRIES, 2018. Disponível em: <http://www.cries.org>. Acesso em: 14 jun. 2018.

EDER. Julia Theresa. The Bolivarian Alliance of the Peoples' of Our America - People's Trade Treaty (ALBATCP1) as a Model for an Alternative EU Trade Agenda? Working Paper. Linz: Johannes Kepler Universität. Disponível em: $<$ http://www.oefse.at/fileadmin/content/Downloads/tradeconference/Eder_ALBATCP_as_a_model_for_an_alternative_EU_trade_agenda.pdf [? 2016]>. Acesso em: 10 mai. 2018.

FREITAS, William Daldegan de. Aliança bolivariana para os povos de nossa América (ALBA): as particularidades de um projeto inovador. $3^{\circ}$ Encontro Nacional ABRI, 2011.

IDOETA. Paula Adamo. Para que servem tantos blocos e grupos regionais? BBC Brasil, 02 de dezembro de $2011 . \quad$ Disponível em: $<$ http://www.bbc.com/portuguese/noticias/2011/12/111201_blocosregionais_pai.shtml, 2011>. Acesso em: jan. 2018.

MORGENFELD, Leandro. Obama, Trump y Clinton, enredados con el TPP. Estados Unidos Hoy: Perspectivas $\quad$ Sudamericanas, $2016 . \quad$ Disponível em: <http://ri.conicet.gov.ar/bitstream/handle/11336/39840/CONICET_Digital_Nro.7ebf364d6269-4cdf-b2a7-7d863ec37145_A.pdf?sequence=2\&isAllowed=y>. Acesso em: 15 fev. 2018.

RICHARD, Yann. Integração regional, regionalização, regionalismo: as palavras e as coisas, Confins [Online], n. 20, 2014. Disponível em: <http://journals.openedition.org/confins/8939>. Acesso em: mar. 2017. DOI: 10.4000/confins.8939.

RIGGIROZZI, Pia \& TUSSIE, Diana. Claves para ler al regionalismo sudamericano: fortalecendo el estado, regulando el mercado, gestionando autonomia. Perspectivas - Revista de Ciencias Sociales, ano 3, n. 05, jan-jun, 2018. Disponível em: $<$ https://www.perspectivasrcs.com/no-5>. Acesso em: 22 jul. 2018. 
SANAHUJA, José Antonio. Enfoques diferenciados y marcos comunes en el regionalismo latinoamericanao: alcance y perspectivas de Unasur e Celac. Pensamiento Propio, $\mathrm{n}^{\circ} 39$, ene-jun de 2014. Buenos Aires: CRIES. Disponível em: <http://www.cries.org/wpcontent/uploads/2014/06/007-Sanahuja.pdf>. Acesso em: 18 mai. 2018.

SARAIVA, Miriam Gomes. Integração regional na América do Sul: processos em aberto. $3^{\circ}$ Encontro Nacional ABRI, 2011. Disponível em: $<$ http://www.proceedings.scielo.br/scielo.php?pid=MSC0000000122011000300028\&script=s ci_arttext>. Acesso em: 7 abr. 2018.

. Estancamento e crise da liderança do Brasil no entorno regional. In: Anuario de la Integración Regional de América Latina y el Caribe, 2016, Edición Especial. Andrés Serbin (Coordinador). CRIES, Buenos Aires, 2016.

TURZI, Mariano. El Acuerdo Transpacífico, ¿una amenaza a la integración latinoamericana. Nueva Sociedad, Outubro, 2015. Disponível em: <http://nuso.org/articulo/el-acuerdotranspacifico-una-amenaza-la-integracion-latinoamericana>. Acesso em: 12 abr. 2018.

ZACCATO, Carolina. EI TPP-11: Oportunidades y desafíos para el regionalismo sudamericano. Perspectivas - Revista de Ciencias Sociales, ano 3 n. 5, jan-jun, 2018. Disponível em: $<$ https://rephip.unr.edu.ar/bitstream/handle/2133/11495/Zaccato.pdf?sequence=3\&isAllowed $=y>$. Acesso em: 17 jul. 2018. 